\title{
A comparison study of percutaneous endoscopic decompression and posterior decompressive laminectomy in the treatment of thoracic spinal stenosis
}

\author{
Xiao-Kang Cheng ${ }^{1,2+}$ D , Fu-Cheng Bian ${ }^{1,2+}$, Zhao-Yu Liu ${ }^{1,2}$, Feng-Kai Yang ${ }^{1,2}$ and Bin Chen ${ }^{1 *}$ [D
}

\begin{abstract}
Background: Percutaneous endoscopic decompression (PED) is considered a minimally invasive and safe procedure in lumbar degenerative disease. Few authors report the success of PED for thoracic spinal stenosis (TSS) with thoracic myelopathy. The objective of this study was to compare the outcome of PED versus posterior decompressive laminectomy (PDL) for TSS.

Methods: We retrospectively reviewed 30 consecutive patients who underwent surgery for single-level TSS from January 1, 2015 to May 1, 2019.These patients were divided into PED $(n=16)$ and PDL $(n=14)$ group. Preoperative demographic characteristics and perioperative outcomes were reviewed. Pre- and postoperative neurological status was evaluated using the modified Japanese Orthopaedic Association (mJOA) score and the recovery rate (RR).

Results: The patients' mean age was 57.3 years (27-76) in PED group and 58.8 years (34-77) in PDL group. No statistical difference was found between two groups with regards to neurological status at pre-operative and final follow-up. The RR in PED group achieved the same improvement as PDL group (87.5\% vs $85.7 \%, P>0.05)$, while the PED brought advantages in operative time $(\mathrm{m})$ (86.4 vs 132.1, $p<0.05)$, blood loss ( $\mathrm{mL}$ ) (18.21 vs 228.57, $p<0.05)$, drainage volume $(\mathrm{mL})(15.5$ vs $601.4, p<0.05)$, and hospital stay (d) (3.6 vs $5.6, p<0.05)$.

Conclusions: Both PED and PDL showed favorable outcome in the treatment of TSS. Besides, PED had advantages in reducing traumatization. In terms of perioperative quality of life, PED could be an efficient supplement to traditional posterior decompressive laminectomy in patients with TSS.
\end{abstract}

Keywords: Thoracic spinal stenosis (TSS), Percutaneous endoscopic decompression (PED), Posterior decompressive laminectomy (PDL), Thoracic myelopathy

\footnotetext{
*Correspondence: drchenbin@vip.sina.com; drcxkz1x@163.com

${ }^{+}$Xiao-Kang Cheng and Fu-Cheng Bian are co-first authors

'Department of Spine Surgery, Chengde Medical University Affiliated Hospital, Chengde 067000, Hebei Province, China

Full list of author information is available at the end of the article
}

C C The Author(s). 2020 Open Access This article is licensed under a Creative Commons Attribution 4.0 International License, which permits use, sharing, adaptation, distribution and reproduction in any medium or format, as long as you give appropriate credit to the original author(s) and the source, provide a link to the Creative Commons licence, and indicate if changes were made. The images or other third party material in this article are included in the article's Creative Commons licence, unless indicated otherwise in a credit line to the material. If material is not included in the article's Creative Commons licence and your intended use is not permitted by statutory regulation or exceeds the permitted use, you will need to obtain permission directly from the copyright holder. To view a copy of this licence, visit http://creativecommons.org/licenses/by/4.0/. The Creative Commons Public Domain Dedication waiver (http://creativecommons.org/publicdomain/zero/1.0/) applies to the data made available in this article, unless otherwise stated in a credit line to the data. 


\section{Background}

Thoracic spinal stenosis (TSS) with thoracic myelopathy. Usually caused by thoracic ossification of the posterior longitudinal ligament or ligamentum flavum, and intervertebral disc herniation, is a reduction of the spinal canal with associated compression of the thoracic spinal cord [1]. Diagnosis is often difficult owing to myriad presenting symptoms including difficulty walking, local pain, sphincter dysfunctions, and lower extremity numbness and weakness [2].

The major studies show that conservative therapy is not effective in TSS with myelopathy to prevent the sequelae of spinal cord compression. Traditional open spinal decompression, involving spinous process and paraspinal muscle dissection, en bloc resection of lamina and removal of the intervertebral disc herniation and hyperplastic ligament, is the prevailing therapy [3, 4]. Although with positive results, there are risks of kyphosis, the adjacent segment degeneration (ASD), and catastrophic neurological deterioration [5]. Based on improvements in optical technology and equipment, good outcomes and advantages of PED for lumbar degenerative disease have been used in recent years $[6,7]$. However, there were few reports of PED for the treatment of TSS $[8,9]$. The objective of this study was to compare the outcome of PED versus PDL for TSS.

\section{Methods}

\section{Patient population}

This study was approved by the Ethics Committee of our hospital, written informed consent was obtained. From January 1, 2015 and May 1, 2019, 30 consecutive patients underwent surgery for single-level TSS, including 16 patients who underwent PED and 14 patients who underwent PDL. Inclusion criteria: patients with single-segment TSS confirmed by MRI and CT. Exclusion criteria: Combined with lumbar or cervical degenerative disease. Preoperative demographic characteristics, perioperative outcomes and neurological status were recorded. The full percutaneous endoscopic spine system, bipolar radiofrequency system, and endoscopic instruments (MaxMorespine GmbH, Germany) were used in PED.

\section{Surgical technique}

For PED group, the surgical procedure was performed below (Based on T10-11 Segment of OLF):

After positioning in the prone position, local anesthesia was used to allow for communication between the surgeon and patient during the procedure. The entry point was $3-5 \mathrm{~cm}$ from the midline. After anesthesia the skin, a spinal needle was introduced (Fig. 1). The needle was positioned at the trailing edge of the lamina and at the medial margin of the facet joint. A series of obturators were inserted along the needle. A

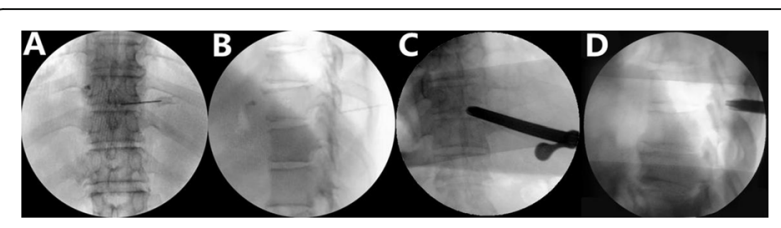

Fig. 1 The Spinal needle and bevelled cannula. a c The needle and cannula was placed on medial margin in anteroposterior view. b d The needle and cannula was placed on the lamina in lateral view

bevelled cannula was inserted along the obturators. The procedure was conducted with solution. After removing the tissue attached with the lamina with the endoscopic instruments, an endoscopic drill was used to expose the lamina completely. After that, a diamond drill was used to thin the OLF (Fig. 2). Then the endo forceps were used to remove the OLF carefully untill the bilateral sides of dural sac and nerve roots were checked and exposed. All endoscopic instruments were taken out, and the incision was closed with or without a suction drainage.

For PDL group, the surgical procedure was performed as described below (en bloc decompression):

The surgical method and steps were consistent with that reported in the literature [4]. To reduce the edema, inflammation and avoid neurological dysfunction, antiinflammatory medication and neuronutrition were given after operation.

\section{Evaluation indicators}

Preoperative demographic characteristics and perioperative outcomes were compared. Neurological status were evaluated using the mJOA score. Neurological recovery was assessed based on the RR. The RR = (postoperative preoperative mJOA score $) /(11$-preoperative mJOA score) $\times 100$. A score of $0-24 \%$ was poor; $25-49 \%$, fair; $50-74 \%$, good; and $75-100 \%$, excellent [10].

\section{Statistical method}

Statistical assessments were analyzed using the SPSS 21 program (USA, IBM corporation). The independent samples t-test and chi-squared test were used to evaluate preoperative demographic characteristics and perioperative outcomes, and repeated-measures analysis of variance was used to evaluate mJOA between the two groups. $P<0.05$ was considered significant.

\section{Results}

Perioperative outcomes and preoperative demographic characteristics

We kept in contact with all of the 30 patients (16 in PED group and 14 in PDL group) throughout the follow-up. Preoperative demographic characteristics were similar in the two groups as shown in Table 1 . 


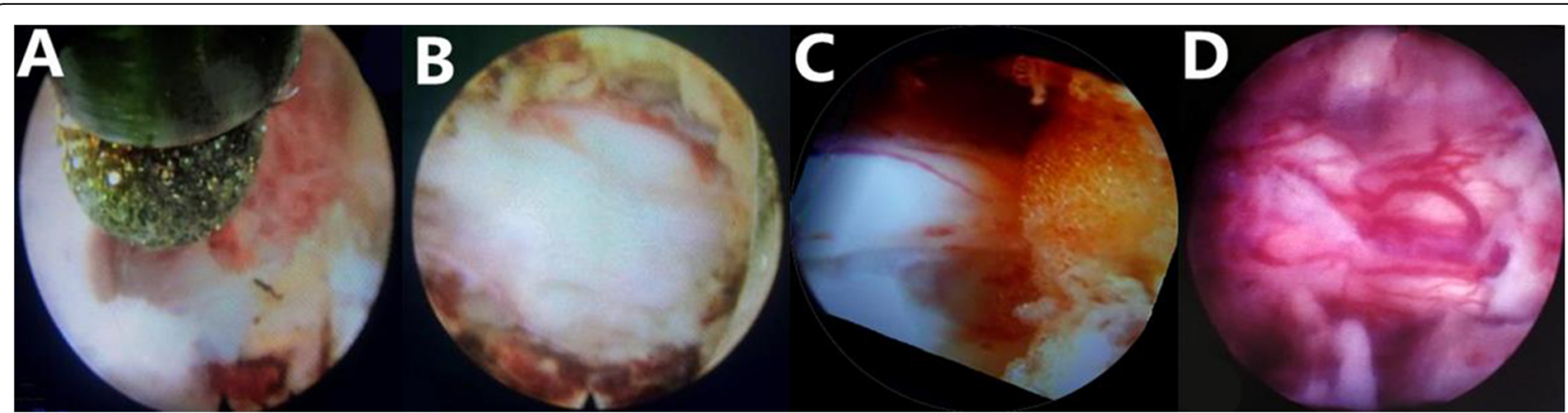

Fig. 2 Intraoperative views. a The diamond abrasor drilling the lamina. b After the OLF were removed by endoscopic instruments, the dura sac was visible. $\mathbf{c}$ The nerve root was exposed. $\mathbf{d}$ The whole dura sac was exposed (white area) and fluctuated well

Perioperative outcomes, including operative time, blood loss, drainage volume and hospital stay time, were recorded as shown in Table 2. PED had advantages in operative time (minutes) (86.4 vs 132.1, $p<0.05)$, blood loss $(\mathrm{mL})(18.2$ vs $228.6, p<0.05)$,drainage volume $(\mathrm{mL})$ (15.5 vs $601.4, p<0.05$ ), hospital stay (days) (3.6 vs 5.6 , $p<0.05)$.

\section{Clinical results}

Statistically improvements in clinical outcomes before surgery to 3,6 , and 12 months after surgery were estimated by the mJOA score and RR (Fig. 3). Both groups had similar improvement in the mean mJOA scores at each follow-up time point $(P<0.05)$. In the preoperative stage, the mean mJOA scores were similar between the 2 groups $(6.0 \pm 1.4$ vs $5.9 \pm 0.9, P<$ 0.05). The mean mJOA scores of the PED group improved to $9.5 \pm 1.3$ at the last follow-up $(P<0.05)$. The mJOA scores also improved significantly in the PDL group to $9.1 \pm 1.0$ at the last follow-up $(P<0.05)$.
Moreover, there were no intergroup differences at any follow-up time point between groups $(P>0.05)$. Good-to-excellent rate was no differences at the final follow-up $(87.5 \%$ vs $85.7 \%, P>0.05)$.

\section{Complications}

In the PED group, one case had dural tear but no cerebrospinal fluid leakage occurred. In PDL group, one patient had dural tear and cerebrospinal fluid leakage. One patient had cerebrospinal fluid leakage and incision infection, which resolved after debridement and antibiotic therapy. One case experienced neurological deterioration. There were no reports of cyst or incision dehiscence, thrombophlebitis,kyphosis or vascular injury during their follow-up.

\section{Discussion}

The aim of this retrospective research was to evaluate and compare the outcome of PED and PDL in geriatric patients with TSS. Although no significant difference

Table 1 Preoperative demographic characteristics

\begin{tabular}{llll}
\hline Characteristics & PED Group $(\boldsymbol{n}=\mathbf{1 6})$ & PDL Group $(\boldsymbol{n}=\mathbf{1 4})$ & \multicolumn{1}{c}{$\boldsymbol{P}$ Value } \\
\hline Age (years) & $57.3 \pm 14.4$ & $58.8 \pm 9.4$ & $>0.05$ \\
Sex (male) & 9 & $6.1 \pm 7.9$ & $>0.05$ \\
Duration of symptoms (months) & $7.1 \pm 7.4$ & \\
Level & 0 & 2 \\
T6-7 & 2 & 1 \\
T8-9 & 2 & 0.05 \\
T9-10 & 3 & 4 \\
T10-11 & 9 & 7 \\
T11-12 & $13 / 16$ & $13 / 14$ \\
Comorbidities & 8 & 8 \\
Hypertension & 3 & 3 \\
Diabetes & 1 & 2 \\
Heart diseases & 2 & 1 \\
Pulmonary & & \\
\hline
\end{tabular}


Table 2 Perioperative outcomes

\begin{tabular}{llll}
\hline Characteristics & PED Group $(\boldsymbol{n}=\mathbf{1 6})$ & PDL Group $(\boldsymbol{n}=\mathbf{1 4})$ & $\boldsymbol{P}$ Value \\
\hline Blood loss $(\mathrm{mL})$ & $18.2 \pm 3.2$ & $228.6 \pm 120.4$ & 0.00 \\
Duration of surgery (minutes) & $86.4 \pm 18.2$ & $132.1 \pm 19.7$ & 0.00 \\
Hospital stay (day) & $3.6 \pm 0.8$ & $5.6 \pm 1.7$ & 0.00 \\
Drainage $(\mathrm{mL})$ & $15.5 \pm 6.9$ & $601.4 \pm 371.7$ & 0.00 \\
Complications & $1 / 16$ & $3 / 14$ & $>0.05$ \\
\hline
\end{tabular}

was found in clinical results between both groups, the PED techniques brought advantages in terms of faster recovery, less trauma, and less complications from our own experience.

It has been reported that the lower thoracic spine is the most frequently affected segment while the upper and mid-thoracic vertebrae are rarely affected within the thoracic spine. This propensity was also seen in this retrospective research.

The traditional surgical methods for TSS are laminotomy with or without fusion $[4,11]$. The procedures depends on general physical condition of patient and TSS type according to CT and MRI evaluation [12]. Some have recommended laminoplasty for the treatment of TSS. However, laminoplasty, merely expands the volume of the spinal canal and does not remove the posterior longitudinal ligament or ligamentum flavum, and intervertebral disc herniation, is not suitable for severe TSS because the procedure sometimes leads to an insufficient decompression and is technically difficult due to the adherence of the OLF to the dura mater. Furthermore, lamina treated with laminoplasty may return to the preoperative position.

At present, laminectomy with or without fusion is the most popular procedure for TSS [13]. It has been considered an effective method for TSS with myelopathy to undergo PDL with or without fusion [14]. Some authors $[15,16]$ have recommended laminectomy with fusion in the treatment of TSS for that instability of the thoracic spine was caused by excessive removal of the lamina and facet joint [11], and therefore it sometimes required pedicle screw fixation and fusion. Although laminectomy achieves a good spinal cord decompression, it comes at the price of multiple complications such as increased incidence of acute neurological deterioration, dura tear, and kyphosis. Since the patients are particularly geriatric who frequently have comorbidities, to consider the necessity for more extensive surgery associated with fusion is vital. Besides, some authours have concluded that decompression alone has lower costs than fusion.

Microendoscopic decompression (MED) treating TSS also has been reported by Baba [17]. Although with a surgeon-friendly view, it requires partial facet joint resection and general anesthesia, which is similar to the traditional open approach. So an effective and less invasive surgical technique is warranted. PED has been popular in the treatment of lumbar degenerative disease because of development of endoscopic instruments and increased patient demand [18]. PED is less invasive than MED for selected patients with lumbar degenerative disease $[19,20]$. Jia $[8]$ performed the PED for the treatment of one OLF case at T2/3. Miao [9] also reported successful PED in treating two cases with unilateral OLF at $\mathrm{T} 9 / 10$ and $\mathrm{T} 3 / 4$ using the PED with paramedian approach.

The postoperative outcomes showed that preoperative symptoms were relieved and the decompression was completed without severe complications (Figs. 4 and 5). The PED requires only a incision of approximately 7.5 $\mathrm{mm}$, with the advantages of causing little damage to the

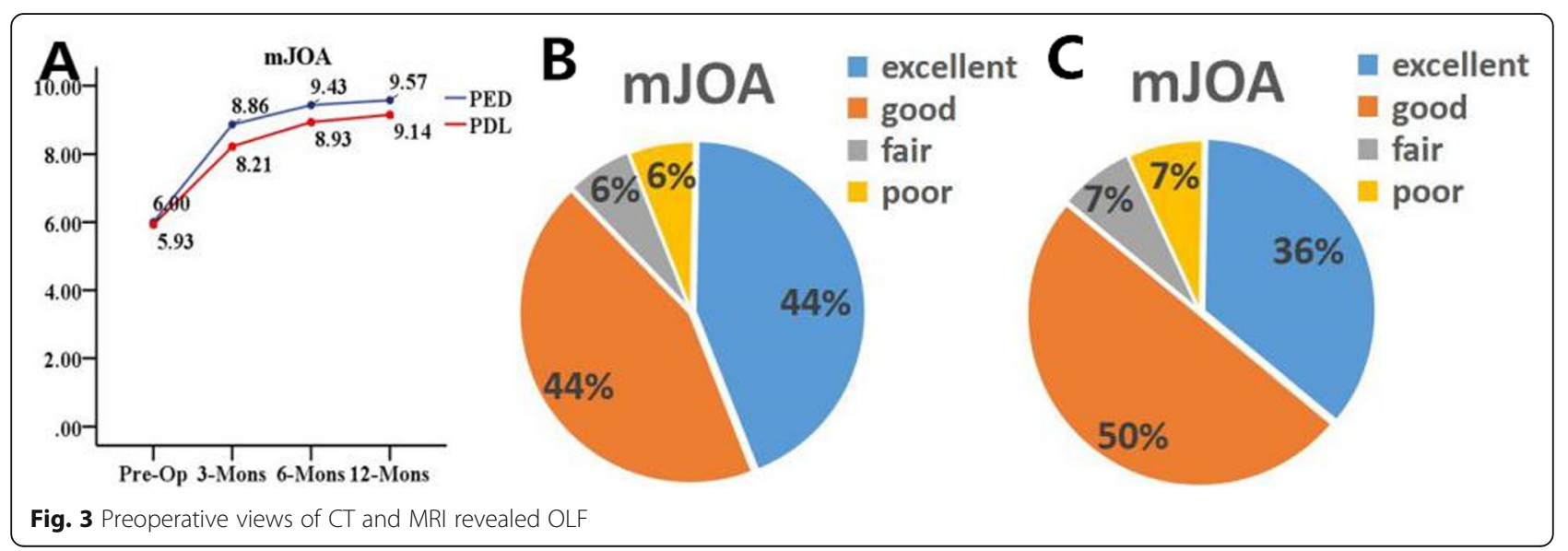



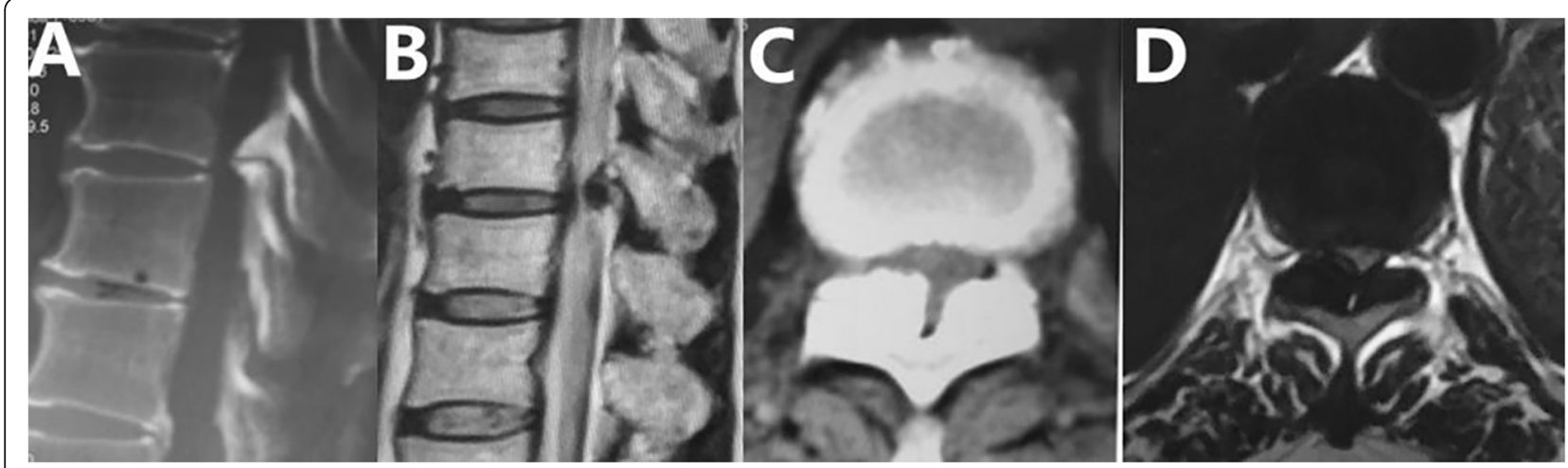

Fig. 4 Postoperative CT and MRI. Satisfactory decompression was performed

paraspinal muscles, dissecting less tissue, and reducing operative time and blood loss. Little lamina and facet joint was removed, therefore no instability of the spine was caused. Pedicle screw fixation and fusion may be unnecessary, the medical costs may be reduced. Moreover, PED can reduce the length of hospitalization [21]. Besides, it can provide clear visualization with saline solution, which is helpful in improving safety of the elderly patients [22]. The surgeons can receive feedback during the operation to reduce the risks of anesthesia related complications and avoiding acute neurological deterioration when removing the OLF and disc herniation with endoscopic instruments. For developing countries, it is very benefcial to economically disadvantaged patients if general anaesthesia with neuromonitoring is not necessary. Moreover, compared with PDL, PED can shorten patients recovery time markedly. Therefore, this procedure could be an effective choice for geriatric patients for whom general anesthesia would be harmful. As for patients with OLF, we can use the diamond high-speed drill to thin the OLF with clear and enlarged visualization as called floating method. Some authors suggested that it could be used to avoid dural tears if the floating method were used [23].
Neurological deterioration is a serious complication for TSS [24]. Some authors reported that the incidence of perioperative neurological deterioration was as high as $14.5 \%$. The insertion of even a $1-\mathrm{mm}$ Kerrison rongeur into the thoracic canal may cause catastrophic neurological deterioration. Therefore, it is dangerous to remove the lamina with a Kerrison rongeur in the thoracic spine. So, in the process of thoracic laminectomy and spinal cord decompression, we should be very careful, which may cause more time and bleeding than open lumbar decompression. In PDL group, one case experienced neurological deterioration after recovery from anesthesia. Although with use of methylprednisolone and functional exercises, the patient condition was not satisfied at final follow-up.

One of the most common complications of the traditional open spinal decompression is CSF leakage [24]. Although not repaired, no cerebrospinal fluid leakage occurred after endoscopic decompression for one case who had intraoperative dural tears in the PED group. In the PDL group, two cases had CSF leakage after the operation, one of whom had incision infection, which resolved after debridement and antibiotic therapy. Although the recovery was good, the process was painful.

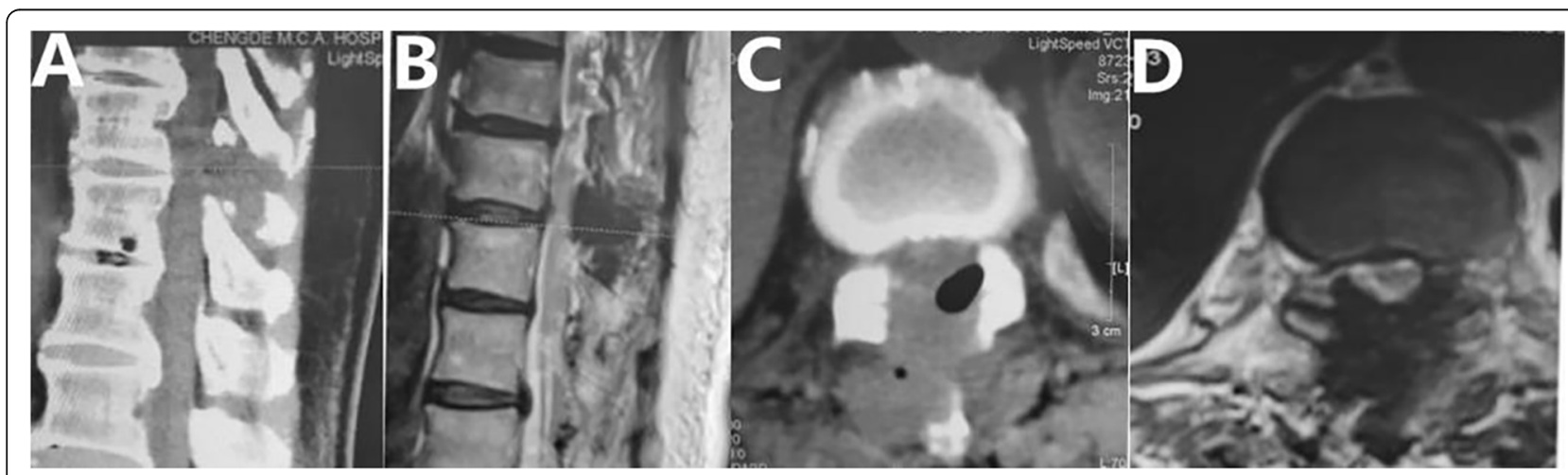

Fig. 5 Clinical outcomes. a mJOA scores. b c Outcome of the RR 
We do not recommend that beginners perform PED independently for the flat learning curve. However, with proper diagnosis, precise indication, and good training, experienced skilled surgeons can use the PED to treat TSS. The primary limitations of the retrospective study are the relatively small number of patients and following time.

\section{Conclusion}

Both PED and PDL showed favorable outcomes for the treatment of single-level TSS. In terms of perioperative quality of life, PED under local anesthesia can be considered as the effective alternatives to traditional open spinal decompression. However, prospective, randomized, controlled trials with a larger sample size and longer follow-up are required in the future.

\section{Acknowledgements}

Not applicable.

\section{Authors' contributions}

Author XK C, B C designed the study. Author XK C, FC B, ZY L and FK Y collected the clinical data and conducted the statistical analysis. Author XK C wrote the manuscript. Author XK C, C B revised the manuscript; All authors critically read the manuscript to improve intellectual content. All authors read and approved the final manuscript.

\section{Funding}

This study supported by the Department of Health of Hebei Province (20150019). The funders had no role in study design, data collection or analysis, decision to publish, or preparation of the manuscript.

\section{Availability of data and materials}

The datasets used and/or analysed during the current study are available from the corresponding author on reasonable request.

\section{Ethics approval and consent to participate}

This research was approved by the ethics committee of Chengde Medical University Affiliated Hospital. All participants agreed with the data and publication of the manuscript.

\section{Consent for publication}

Written informed consent was obtained from all participants.

\section{Competing interests}

The authors declare that they have no competing interests.

\section{Author details}

${ }^{1}$ Department of Spine Surgery, Chengde Medical University Affiliated Hospital, Chengde 067000, Hebei Province, China. ${ }^{2}$ Chengde Medical University, Chengde 067000, Hebei, China.

Received: 17 May 2020 Accepted: 23 October 2020

Published online: 03 November 2020

\section{References}

1. Aizawa T, Sato T, Tanaka Y, et al. Thoracic myelopathy in Japan: epidemiological retrospective study in Miyagi prefecture during 15 years. Tohoku J Exp Med. 2006;210:199.

2. Hou X, Sun C, Liu X, et al. Clinical features of thoracic spinal stenosisassociated myelopathy: a retrospective analysis of 427 cases. Clin Spine Surg. 2016;29(2):86-9.

3. Jia LS, Chen XS, Zhou SY, et al. En bloc resection of lamina and ossified ligamentum flavum in the treatment of thoracic ossification of the ligamentum flavum. Neurosurgery. 2010;66(6):1181-6.
4. Wang $\mathrm{CH}$, Cui $W L$, Xue $J$, et al. Transforaminal en bloc resection for the treatment of thoracic ossification of the ligamentum flavum: retrospective cohort study. Int J Surg. 2018;54(Pt A):278-84.

5. Wang T, Yin C, Wang D, et al. Surgical technique for decompression of severe thoracic myelopathy due to tuberous ossification of Ligamentum Flavum. Clin Spine Surg. 2017;30(1):E7-E12.

6. Xiong C, Li T, Kang H, et al. Early outcomes of 270-degree spinal canal decompression by using TESSYS-ISEE technique in patients with lumbar spinal stenosis combined with disk herniation. Eur Spine J. 2019;28(1): 78-86.

7. Minamide A, Simpson AK, Okada M, et al. Microendoscopic decompression for lumbar spinal stenosis with degenerative Spondylolisthesis: the influence of Spondylolisthesis stage (disc height and static and dynamic translation) on clinical outcomes. Clin Spine Surg. 2019;32(1):E20-6.

8. Jia ZQ, He XJ, Zhao LT, et al. Transforaminal endoscopic decompression for thoracic spinal stenosis under local anesthesia. Eur Spine J. 2018;27(Suppl 3): 465-71.

9. Miao X, He D, Wu T, et al. Percutaneous endoscopic spine minimally invasive technique for decompression therapy of thoracic myelopathy caused by ossification of the Ligamentum Flavum. World Neurosurg. 2018;114:8-12.

10. Yonenobu K, Ebara S, Fujiwara K, et al. Thoracic myelopathy secondary to ossification of the spinal ligament. J Neurosurg. 1987;66(4):511-8.

11. Okada K, Oka S, Tohge K, et al. Thoracic myelopathy caused by ossification of the ligamentum flavum. Clinicopathologic study and surgical treatment. Spine (Phila Pa 1976). 1991;16(3):280-7.

12. Ikuta K, Tarukado K, Senba H, et al. Decompression procedure using a microendoscopic technique for thoracic myelopathy caused by ossification of the ligamentum flavum. Minim Invasive Neurosurg. 2011; 54(5-6):271-3.

13. Ando K, Imagama S, Kaito $T$, et al. Outcomes of surgery for thoracic myelopathy owing to thoracic ossification of the Ligamentum Flavum in a Nationwide multicenter prospectively collected study in 223 patients: is instrumented fusion necessary? Spine (Phila Pa 1976). 2020;45(3):E170-8.

14. Wang $H$, Wei $F$, Long $H$, et al. Surgical outcome of thoracic myelopathy caused by ossification of ligamentum flavum. J Clin Neurosci. 2017;45: 83-8.

15. Liao CC, Chen TY, Jung SM, et al. Surgical experience with symptomatic thoracic ossification of the ligamentum flavum. J Neurosurg Spine. 2005; 2(1):34-9.

16. Wang $Y$, Yang $L$, Lei $T$, et al. Benefits and risks of subsection laminectomy with pedicle screw fixation for ossification of the Ligamentum Flavum of the thoracic spine: a retrospective study of 30 patients. Med Sci Monit. 2019;25:6341-50.

17. Baba S, Oshima Y, Iwahori T, et al. Microendoscopic posterior decompression for the treatment of thoracic myelopathy caused by ossification of the ligamentum flavum: a technical report. Eur Spine J. 2016; 25(6):1912-9.

18. Youn MS, Shin JK, Goh TS, et al. Endoscopic posterior decompression under local anesthesia for degenerative lumbar spinal stenosis. J Neurosurg Spine. 2018;29(6):661-6.

19. Yoon SM, Ahn SS, Kim KH, et al. Comparative study of the outcomes of percutaneous endoscopic lumbar discectomy and microscopic lumbar discectomy using the tubular retractor system based on the VAS, ODI, and SF-36. Korean J Spine. 2012;9(3):215-22.

20. Kim HS, Paudel B, Jang JS, et al. Percutaneous full endoscopic bilateral lumbar decompression of spinal stenosis through Uniportal-contralateral approach: techniques and preliminary results. World Neurosurg. 2017; 103:201-9.

21. Xiaobing Z, Xingchen $L$, Honggang $Z$, et al. "U" route transforaminal percutaneous endoscopic thoracic discectomy as a new treatment for thoracic spinal stenosis. Int Orthop. 2019;43(4):825-32.

22. Song HP, Sheng HF, Xu WX. A case-control study on the treatment of protrusion of lumbar intervertebral disc through PELD and MED. Exp Ther Med. 2017;14(4):3708-12

23. Miyashita T, Ataka H, Tanno T. Spontaneous reduction of a floated ossification of the ligamentum flavum after posterior thoracic decompression (floating method); report of a case (abridged translation of a primary publication). Spine J. 2013;13(8):e7-9. 
24. Osman NS, Cheung ZB, Hussain AK, et al. Outcomes and complications following laminectomy alone for thoracic myelopathy due to ossified

Ligamentum Flavum: a systematic review and meta-analysis. Spine (Phila Pa 1976). 2018;43(14):E842-8.

\section{Publisher's Note}

Springer Nature remains neutral with regard to jurisdictional claims in published maps and institutional affiliations.

Ready to submit your research? Choose BMC and benefit from:

- fast, convenient online submission

- thorough peer review by experienced researchers in your field

- rapid publication on acceptance

- support for research data, including large and complex data types

- gold Open Access which fosters wider collaboration and increased citations

- maximum visibility for your research: over $100 \mathrm{M}$ website views per year

At BMC, research is always in progress.

Learn more biomedcentral.com/submissions 